\title{
POSSIBILITIES FOR MORE ACCURATE PREDICTION OF THERMAL INJURY SEVERITY AND DETERMINATION OF ITS IMPACT ON THE BODY USING THE ABBREVIATED BURN SEVERITY INDEX
}

\author{
Emiliya Kaisheva ${ }^{1}$, Dobrinka Radoynova ${ }^{1}$, Yolanda Zayakova ${ }^{2}$ \\ ${ }^{1}$ Department of Forensic Medicine and Deontology, Faculty of Medicine, \\ Medical University of Varna \\ ${ }^{2}$ Clinic of Thermal Trauma, Plastic, Reconstructive and Aesthetic Surgery, \\ Naval Hospital of Varna, Military Medical Academy of Sofia
}

\begin{abstract}
INTRODUCTION: During the last decades, the chances of survival in burn patients have been progressively increasing, but the issue of prognosis of death after such injuries is still of great ethical, social, medical, and forensic interest.

AIM: The purpose of our study was to examine and confirm the accuracy of the ABSI (Abbreviated Burn Severity Index) system in predicting the risk of death in thermal trauma by comparing its values with the actual risk reported.

MATERIALS AND METHODS: In order to achieve this purpose, the medical records of burn patients admitted to the Clinic of Thermal Trauma, Plastic, Reconstructive and Aesthetic Surgery at the Naval Hospital of Varna for a five-year period (2011-2015) were studied and the death cases were analyzed. The mortality rate predicted by $\mathrm{ABSI}$ was compared to the actual death rate reported in the medical records.

RESULTS: There was a significant difference in the mean values of ABSI in survivors and deceased: 4.65 and 11, respectively. All with an ABSI value less than 3 survived. For ABSI values up to 10, a slightly lower mortality was reported than the predicted. For the values $\geq 11$ they matched. Despite these discrepancies, we believe that ABSI is suitable for calculating the risk of death in thermal trauma, especially in more severe burns, where the threat to life is higher.
\end{abstract}

CONCLUSION: Three groups were differentiated with a sharp increase in the percentage of actually reported mortality. Their respective ABSI values can be taken as a reference for forensic medical practitioners in the classification of bodily injuries due to burns.

Keywords: thermal injury, scoring systems, ABSI, trauma assessment, bodily injury

Address for correspondence:

Emiliya Kaisheva

Department of Forensic Medicine and Deontology

Medical University of Varna

55 Marin Drinov St

9002 Varna

e-mail:emiliakaisheva@gmail.com

Received: June 19, 2018

Accepted: September 19, 2018

\section{INTRODUCTION}

During the last decades, the chances of survival in burn patients have been progressively increasing, due to better knowledge of their pathophysiology as well as better management of risk situations through adequate reanimation and treatment including effective surgery of the traumatized tissue, use of synthetic and natural skin replacements, etc. (1-8). However, the issue of prognosis of death after such inju- 
Possibilities for More Accurate Prediction of Thermal Injury Severity and Determination of Its Impact on the Body ...

ries is still of great ethical, social, medical, and forensic interest. It concerns both the injured person and the medical team involved in the treatment, the relevant health and social organizations and the forensic medical practitioner who has to determine the type of bodily injury (1,5,9-11). This created the need to introduce a prognostic system whose usefulness is determined by prognostic accuracy - the more accurate, the more useful. At the same time, the use of accurate but complex to compute indexes created using computer systems has its inconveniences. The formula for predicting fatal outcome should have a sufficiently high accuracy but also be as simple as possible to be applicable in day-to-day clinical and forensic practice $(1,9,12-15)$. Therefore, it should be based on a minimum number of easily determined indicators. Factors influencing prognosis in burn patients are: age, sex, burn degree and burn area, previous diseases, connected with injuries and inhalation disabilities. A classic example (and perhaps the most common) for calculating the probability of death is the sum of the patient's age and the percentage of the total body surface area burned (1,6,15-21). This formula is easy to remember, but it includes only two of the mentioned factors. In contrast, the ABSI system consists of a sum of five variables which are determined by different researchers to be the most im-

Table 1. ABSI score

\begin{tabular}{l|cc}
\hline Variable & & Score \\
Sex & Female & 1 \\
& Male & 0 \\
& $0-20$ & 1 \\
Age /years/ & $21-40$ & 2 \\
& $41-60$ & 3 \\
Inhalation injury & $61-80$ & 4 \\
Full thickness burn & $81-100$ & 5 \\
& & 1 \\
& $1-10$ & 1 \\
& $11-20$ & 1 \\
TBSA /\%/ & $21-30$ & 2 \\
& $31-40$ & 3 \\
& $41-50$ & 4 \\
& $51-60$ & 5 \\
& $61-70$ & 6 \\
& $71-80$ & 8 \\
& $81-90$ & 9 \\
\hline
\end{tabular}

portant for fatal outcome of burns: sex, age, presence of inhalation injury, presence of full thickness burn, percentage of total body surface area burned $(1,15,22$ 26 ). The ABSI score (sum of the points for each variable) shows the survival probability of the patient (Table 1, Table 2).

Table 2. ABSI score and probability of survival

\begin{tabular}{lcc} 
ABSI Score & Threats to Life & $\begin{array}{c}\text { Probability of } \\
\text { Survival } / \% /\end{array}$ \\
\hline $2-3$ & Very low & $\geq 99$ \\
$4-5$ & Moderate & 98 \\
$6-7$ & Moderately severe & $80-90$ \\
$8-9$ & Serious & $50-70$ \\
$10-11$ & Severe & $20-40$ \\
$12-13$ & Maximum & $\leq 10$ \\
\hline
\end{tabular}

Despite the development of a number of different systems for calculating the prognostic risk of fatal outcome in burn patients, no system has been accepted as standard yet. The purpose of our study was to examine and confirm the accuracy of the ABSI system in predicting the risk of fatal thermal injury by comparing the predicted values with the actual outcome. Confirmation of its prognostic value would allow its application in clinical and forensic practice to predict the risk of death and determine the severity of bodily injury as a result of burns.

\section{MATERIALS AND METHODS}

For the purpose of the study, we performed a retrospective analysis: we examined the medical records of burn patients admitted to the CTTPRAS (Clinic of Thermal Trauma, Plastic, Reconstructive and Aesthetic Surgery) at the Naval Hospital of Varna for a five-year period from January $1^{\text {st }}, 2011$ to December $31^{\text {st }}$, 2015. From these we derived the values, necessary for calculating the ABSI indicators: sex, age, presence of inhalation injury, presence of full thickness burn, percentage of total body surface area burned.

In order to determine the percentage of total body surface area burned we used the Wallace rule of nines.

The burn degree was determined using the commonly accepted classification: $1^{\text {st }}, 2^{\text {nd }}$, etc. Firstdegree (superficial) - burns affect only the epider- 
mis, or outer layer of skin. Second-degree (partial thickness - A and B) - burns involve the epidermis and part (A - upper part, B - upper and bottom part) of the dermis layer of skin. Third-degree (full thickness) - burns destroy the epidermis and dermis and may go into the subcutaneous tissue.

The presence of inhalation injury was determined based on the medical records: case history, clinical symptoms and changes in blood-gas analysis.

All cases were divided into two groups according to the outcome of the thermal injury: death or recovery.

The ABSI indicators were calculated for all cases.

Regression analysis was used to determine the impact of each of the examined indicators on mortality and the relationship between actual and predicted mortality. Quantitative (numeral) data were processed using standard statistical methods and summarized in tables.

\section{RESULTS}

For the studied period (2011 - 2015) 2,036 burn patients were admitted to the CTTPRAS at the Naval Hospital of Varna. Seventy-four of them died. The overall mortality rate was $3.6 \%$. Twenty-one patients died in the acute phase (up to 3 days after the accident), 28 - between the $4^{\text {th }}$ and $10^{\text {th }}$ day, 16 - between the $11^{\text {th }}$ and $22^{\text {nd }}$ days, and 9 - more than 22 days after the burn.

The mean age was 40.1 years with a minimum of 1 month and a maximum of 93 years. For the deceased and survived patients the mean values were 62.5 and 39.3 years, respectively.

The determined sex ratio was: 1.4:1, 1,173 men (58\%) and 863 women (42\%). Of all men, 44 (3.9\%) died and 1,129 survived. For the women, these values were: $30(3.6 \%)$ and 833 , respectively.

The average burn area was $8.33 \%$ of the total body surface area, with a minimum of $1 \%$ and a maximum of $100 \%$; the average burn area in deceased being $52.3 \%$ and in survivors $-6.67 \%$.

Presence of full thickness burn was reported in 800 cases. From these, 70 died and 730 recovered.

Presence of inhalation injury was reported in 78 cases. From these, 43 died and 35 survived (55.3\% mortality).
The determined ABSI values in fatal cases were from 4 to 16, with a mean value of 11. In patients who survived the injury and were discharged from the clinic the mean value was 4.65 .

We compared the mortality rate predicted by ABSI with the actual mortality, derived from the records (Table 3).

Table 3. Comparison of the predicted threat to life to the established actual mortality rate at respective ABSI values

\begin{tabular}{lc|c|}
\hline ABSI Score & Threat to Life & Actual Mortality Rate \\
\hline $4-7$ & Moderate & $0.4 \%$ \\
8 & Serious & $9.88 \%$ \\
9 & Serious & $18.18 \%$ \\
10 & Severe & $47.62 \%$ \\
11 & Severe & $78.57 \%$ \\
12 & Maximum & $100 \%$ \\
13 & Maximum & $87.5 \%$ \\
14 & Maximum & $87.5 \%$ \\
15 & Maximum & $100 \%$ \\
16 & Maximum & $100 \%$ \\
\hline \hline
\end{tabular}

\section{DISCUSSION}

In our study we established a connection between fatal outcome in thermal injury and the following risk factors: burn area (\% of total body surface area), presence of full thickness burn, age, sex, presence of inhalation injury, etc., which was similar to other studies on the same subject $(7,9,16,22)$. The overall mortality rate was $3.6 \%$, similar to the reported rate in other related studies $(9,25)$.

The average burn area was $8.33 \%$. Similar data were also reported by other researchers (17), as well as by Ruan et al. (9). The share of the injured who had a burn area of up to $20 \%$ of the total body surface area was $77.5 \%$. Other studies report an average burn area of $42 \%$ (1), but they only examined severe burn cases. We determined the value of this indicator to be $52.3 \%$ in fatal cases and $6.7 \%$ for survivors. This corresponds to other studies, where the average burn area amounts to $49 \%$ for deceased patients (4). The results clearly indicate that larger percentage of burn area is associated with a higher risk of death $(1,6,7,9,11,20,27)$. 
Possibilities for More Accurate Prediction of Thermal Injury Severity and Determination of Its Impact on the Body ...

Burn degree is also important for determining its severity and outcome. In the presence of $3^{\text {rd }}$ degree (full thickness burn), even in a smaller affected area, the damage is more severe and has worse consequences $(4,13,14)$. Some researchers, however, report that it does not have a significant impact on mortality $(11,28)$.

Another indicator relevant for predicting fatal outcome is the age of the patient. The older the age, the greater the probability of death. In these patients, prognosis is more severe, both due to the presence of accompanying diseases as well as different and often extreme pathophysiological stress response $(5,9,11,14,21,26,27,29)$.

Indisputable is also the role of accompanying diseases (cardiovascular, lung, renal, endocrine) and the risk factors for the more severe course and higher mortality after thermal injury. A number of researchers $(5,7,9,20,23,24,26)$ think that they should be taken into account and included in the calculations in order to optimize the prediction of mortality rate in burn patients.

One of the known disadvantages of the ABSI prognostic system is that no special attention is paid to younger children, especially newborns, where it has been proven that the mortality risk, similar to the elderly, is higher $(6,19)$. Other researchers $(8,18,20,25)$ point out that the correlation between age and mortality in children is not high. On the contrary, they report that burn mortality is lower in children and they survive even in severe burn cases.

Some researchers report a difference in the ratio of male and female burn patients of 2:1 $(1,4,26)$. According to other authors $(11,28)$, sex has the least prognostic significance, with almost no difference in the risk of death in both sexes. This corresponds to our results where the ratio of deceased men/women was 3.9:3.6\%. George et al. (12) noticed even a $30 \%$ lower risk of death in male burn patients. There are studies (14) that point to even greater difference three times greater risk of death in women compared to men with thermal injuries.

It was found that the presence of inhalation injury is also important for the fatal outcome in thermal injury $(4,7,18,20,22,27)$. Many researchers $(6,8,9,28,30)$ report the relationship between inhalation injury and higher lethality, which they explain with cardiopulmonary distress in patients with inhalation injuries, not present in those with skin injuries only.

Our study also confirmed that in the presence of inhalation injury, the course of the thermal disease could be more severe and could lead to fatal outcome, even in cases of smaller burn area and lower burn degree. In fact, age, degree, area and presence of inhalation injury are the main four factors that determine burn mortality.

When calculating the ABSI indicator for all thermal injury cases, there was a significant difference in ABSI mean values in survivors and deceased patients: 4.65 and 11; as well as a sharp increase in the number of fatal cases for $A B S I \geq 10$. This corresponds to the results indicated by other researchers - Berndson et al. (10) reported mean ABSI values of 7.7 for survivors and 10.3 for deceased.

When comparing the predicted threat to life with the actual reported, a discrepancy is detected for the low ABSI values and almost full correspondence for the high values. All with an ABSI up to 3 survived. For the rest of the values up to 10 , our study reported a slightly lower mortality rate than the predicted. For the values $\geq 11$ they matched.

Despite the indicated discrepancies, we accept, similar to other researchers $(7,10,22,23)$, that ABSI is suitable for calculating the risk of thermal injury mortality, especially in more severe burns.

When analyzing the results, we have established that the percentage of real mortality increases at certain ABSI values. For values 0 to 3 there are no reported deaths. For 4-9 the mortality is between 0.3 and $18 \%$, and for values $\geq 10$, it is between 50 and $100 \%$. Based on the above results, we suggest these ABSI values be taken as reference for forensic pathologists in classifying bodily burn injury (Table 4).

Table 4. ABSI score and corresponding classification of bodily injury

\section{ABSI Score Qualification}

$\leq 3$

Temporary health disorder not life-threatening

$4-9$

$\geq 10$
Health disorder temporarily life-threatening

Health disorder permanently life-threatening 
Emiliya Kaisheva, Dobrinka Radoynova, Yolanda Zayakova

For values $\geq 12$, the actual mortality rate is 90 $100 \%$. It could be discussed that these values should be accepted not as an indication of a severe bodily injury but as a cause of death in a particularly painful way for the injured person.

\section{CONCLUSION}

The results of this study confirm the specificity and accuracyof ABSI when predicting fataloutcomein thermal injury. Three groups are clearly differentiated according to ABSI values and the rapidly increasing threat to life, allowing their classification into a specific medico-biological indicator of bodily injury. This, along with the relatively simple computational formula, makes ABSI a useful system for daily use in clinical and forensic practice in determining the severity of injury and predicting fatal outcome, and hence the extent of injury caused by thermal trauma.

\section{REFERENCES}

1. Tahir SM, Memon AR, Kumar M, Ali SA. Prediction of mortality after major burn: Physiological versus biochemical measures. Wounds. 2009; 21(7):177-82.

2. Latenser BA. Critical care of the burn patient: the first 48 hours. Crit Care Med. 2009;37(10): 2819-26. doi: 10.1097/CCM.0b013e3181b3a08f.

3. Alvarado R, Chung KK, Cancio LC, Wolf SE. Burn resuscitation. Burns. 2009; 35(1): 4-14. doi: 10.1016/j.burns.2008.03.008.10.

4. Benito-Ruiz J, Navarro-Monzonis A, Baena-Montilla P, Mirabet-Ippolito V. An analysis of burn mortality. A report from a Spanish regional burn centre. Burns. 1991;27(3):201-4.

5. Brusselaers N, Monstrey S, Vogelaers D, Hoste E, Blot S. Severe burn injury in Europe: a systematic review of the incidence, etiology, morbidity, and mortality. Critical Care. 2010;14(5): 188. doi: 10.1186/cc9300.

6. Karimi H, Motevalian SA, Rabbani A, Motabar AR, Vasigh M, Sabzeparvar M. et al. Prediction of mortality in pediatric burn injuries: R-Baux score to be applied in children (pediatrics-baux score). Iran J Pediatr. 2013;23(2):165-70.

7. Lionelli GT, Pickus EJ, Beckum OK, DeCoursey RL, Korentager RA. A three decade analysis of factors affecting burn mortality in the elderly. Burns. 2005,31(8):958-63. doi: 10.1016/j. burns.2005.06.006.
8. Rose JK, Herndon DN. Advances in the treatment of burn patients. Burns. 1997;23(1):19-26.

9. Ryan CM, Schoenfeld DA, Thorpe WP, Sheridan RL, Cassem EH, Tompkins RG. Objective estimates of the probability of death from burn injuries. N Engl J Med. 1998;338(6):362-6. doi: 10.1056/ NEJM199802053380604.

10. Berndtson AE, Sen S, Greenhalgh DG, Palmieri TL. Estimating severity of burn in children: Pediatric Risk of Mortality (PRISM) score versus Abbreviated Burn Severity Index (ABSI). Burns. 2013;39(6): 1048-53. doi: 10.1016/j.burns.2013.05.00.

11. Andel D, Kamolz LP, Niedermayr M, Hoerauf K, Schramm W, Andel H. Which of the abbreviated burn severity index variables are having impact on the hospital length of stay? J Burn Care Res. 2007;28(1):163-6. doi: 10.1097/ BCR.0B013E31802C9E8F.

12. George RL, McGwin G Jr, Schwacha MG, Metzger J, Cross JM, Chaudry IHet al. The association between sex and mortality among burn patients as modified by age. J Burn Care Rehabil. 2005;26(5):416-21.

13. Klein MB, Lezotte DC, Heltshe S, Fauerbach J, Holavanahalli RK, Riara FP et al. Functional and psychosocial outcomes of older adults after burn injury: results from a multicenter database of severe burn injury. J Burn Care Res. 2011;32(1):66-78. doi: 10.1097/BCR.0b013e318203336a.

14. Moore EC, Pilcher DV, Bailey MJ, Stephens H, Cleland H. The Burns Evaluation and Mortality Study (BEAMS): predicting deaths in Australian and New Zealand burn patients admitted to intensive care with burns. J Trauma Acute Care Surg. 2013;75(2):298-303. doi: 10.1097/ TA.0b013e318295409d.

15. Sheppard NN, Hemington-Gorse S, Shelley OP, Philp B, Dziewulski P. Prognostic scoring systems in burns: a review. Burns. 2011;37(8):1288-95. doi: 10.1016/j.burns.2011.07.017.

16. Zawacki BE, Azen SP, Imbus SH, Chang YT. Multifactorial probit analysis of mortality in burned patients. Ann Surg. 1979;189(1):1-5.

17. Tompkins RG, Burke JF, Schoenfeld DA, Bondoc CC, Quinby WC Jr, Behringer GC et al. Prompt eschar excision: a treatment system contributing to reduced burn mortality: a statistical evaluation of burn care at the Massachusetts General Hospital (1974-1984). Ann Surg. 1986;204(3):272-81. 
18. Roberts G, Lloyd M, Parker M, Martin R, Philp B, Shelley $\mathrm{O}$ et al. The Baux score is dead. Long live the Baux score: a 27-year retrospective cohort study of mortality at a regional burns service. J Trauma Acute Care Surg. 2012;72(1):251-6. doi: 10.1097/ TA.0b013e31824052bb.

19. Thombs BD, Singh VA, Milner SM. Children under 4 years are at greater risk of mortality following acute burn injury: evidence from a national sample of 12,902 pediatric admissions. Shock. 2006;26(4):348-52. doi: 10.1097/01. shk.0000228170.94468.e1.

20. Lundgren RS, Kramer CB, Rivara FP, Wang J, Heimbach DM, Gibran NS et al. Influence of comorbidities and age on outcome following burn injury in older adults. J Burn Care Res. 2009;30(2):307-14. doi: 10.1097/ BCR.0b013e318198a416.

21. Wibbenmeyer LA, Amelon MJ, Morgan LJ, Robinson BK, Chang PX, Lewis II R, et al. Predicting survival in an elderly burn patient population. Burns. 2001;27(6):583-90.

22. Tobiasen J, Hiebert JM, Edlich RF. The abbreviated burn severity index. Ann Emerg Med. 1982;11(5):260-2.

23. Horbrand F, Schrank C, Henckel-Donnersmarck G, Muhlbauer W. Integration of preexisting diseases and risk factors in the Abbreviated Burn Severity Index (ABSI). Anasthesiol Intensivmed Notfallmed Schmerzther. 2003;38(3):151-7.
24. McGwin G, Jr., George RL, Cross JM, Rue LW. Improving the ability to predict mortality among burn patients. Burns. 2008; 34(3):320-7. doi: 10.1016/j. burns.2007.06.003.

25. Saffle JR, Davis B, Williams P. Recent outcomes in the treatment of burn injury in the United States: a report from the American burn association patient registry. J Burn Care Rehabil. 1995;16(3): 219-32.

26. Siemers F, Liodaki E, Mauss KL, Stang FH, von Wild T, Mailaender P. Burn Injuries in Elderly - A Retrospective Analysis of a Ten Year Period. Modern Plastic Surgery.2012;2:13-19. doi: 10.4236/ mps.2012.22004.

27. Brusselaers N, Hoste EA, Monstrey S, Colpaert $\mathrm{KE}$, De Waele JJ, Vandewoude KH, et al. Outcome and changes over time in survival following severe burns from 1985 to 2004 . Intensive Care Med. 2005;31(12):1648-53. doi: 10.1007/ s00134-005-2819-6.

28. Andel H, Kamolz LP. Scoring in burned patients our opinion. Burns. 2003;29(4):297-8.

29. McGill V, Kowal-Vern A, Gamelli RL. Outcome for older burn patients. Arch Surg. 2000; 135(3):320-5.

30. Masaki F, Isao T, Hiroshi I, Seiji H, Eisuke S. A case of severe smoke inhalation injury without cutaneous burn required massive fluid for resuscitation. Burns. 2007; 33(5): 670-1. doi: 10.1016/j. burns.2006.07.024. 